\title{
Factors Influencing Attitude, Safety Behavior, and Knowledge regarding Household Waste Management in Guinea: A Cross-Sectional Study
}

\author{
Keita Mamady \\ Department of Epidemiology and Health Statistics, School of Public Health, Central South University, Changsha, Hunan 410078, China \\ Correspondence should be addressed to Keita Mamady; kethmohawassdeh@gmail.com
}

Received 15 December 2015; Accepted 8 March 2016

Academic Editor: Mynepalli K. C. Sridhar

Copyright @ 2016 Keita Mamady. This is an open access article distributed under the Creative Commons Attribution License, which permits unrestricted use, distribution, and reproduction in any medium, provided the original work is properly cited.

\begin{abstract}
Waste indiscriminate disposal is recognized as an important cause of environmental pollution and is associated with health problems. Safe management and disposal of household waste are an important problem to the capital city of Guinea (Conakry). The objective of this study was to identify socioeconomic and demographic factors associated with practice, knowledge, and safety behavior of family members regarding household waste management and to produce a remedial action plan. I found that no education background, income, and female individuals were independently associated with indiscriminate waste disposal. Unplanned residential area was an additional factor associated with indiscriminate waste disposal. I also found that the community residents had poor knowledge and unsafe behavior in relation to waste management. The promotion of environmental information and public education and implementation of community action programs on disease prevention and health promotion will enhance environmental friendliness and safety of the community.
\end{abstract}

\section{Introduction}

Humanity continues to develop and produce cutting-edge products in order to fulfill its most fundamental needs of life. However, the resulting production and consumption of resources end up with prominent problems regarding solid waste generation and management in diverse parts of the world [1]. Developed countries' waste disposal practice includes landfilling, composting, incineration, and pyrolysis [2]. Safe management and disposal of household waste are problems that face some metropolitan cities in Guinea $[3,4]$. Yet, the environmental pollution associated with indiscriminate waste disposal has serious negative impacts on public health and safety $[5,6]$.

The major causes of improper management of solid waste are related to the lack of financial management and logistics, deficient municipal infrastructures, lopsided planning pastures, disregard for basic aesthetics, and industrial and commercial growths as well as the perceptions and sociocultural practices $[7,8]$. Although inadequate management of solid waste might be attributed to numerous factors, it is essential to emphasize the role of community residents, their attitudes, their waste handling practices, and their interactions with other actors in the waste system because they are the main end-users of waste management facilities $[1,9]$. Barrier to solid waste management in Guinea might be quite unique per se in terms of environmental impacts, socioeconomic factors, and cultural heritage, so different areas will find different strategies effective for proper waste management.

Some research studies found that either at-home safety consciousness [9] or knowledge [10] of waste related deleterious health effects is associated with household waste disposal strategy. For example, safety behavior is required to prevent direct contamination and exposure to infectious and injurious substances to health from household waste on the one hand. On the other hand, increasing knowledge can foster positive attitudes and build safe practices among populations. In Guinea, there is a lack of measures aimed at informing the public about the causal connection between environmental pollution and health, and no provision has been made for a long-term evaluation which would make it possible to examine whether the measures are helping to 
reduce environmentally related health problems in a costeffective manner $[3,4]$. Therefore, research and development in waste management should continue to improve data, models, and concepts related to long-term safety of disposal of long-lived waste.

The main objectives of this study were (1) to identify factors associated with abnormal household waste disposal and (2) to assess the household knowledge of the health and safety risks posed by improper disposal of household special waste.

\section{Methods}

2.1. Setting and Population. An interesting aspect to the study is the focus it puts on the largest and most urbanized city of Guinea, Conakry. The city is thought to contain almost a quarter of the population of Guinea. Conakry is a port city on the Atlantic Ocean and serves as the economic, financial, and cultural centre of the country. Its population was estimated in 2014 at 1,667,864 with an area of 450 square kilometers [11]. The city has been experiencing an insufficiency of local waste disposal sites and recycling waste materials [4].

2.2. Sample Description. The study sample was a survey of a cross-sectional, multistage, clustered, stratified, weighted design representative of the population of Conakry. The survey was carried out between February and April 2015. As part of the inclusion criteria, respondents were required to (1) be 15 years old or older, (2) freely consent to participate in the survey, (3) speak French or at least one of the Guinean dialects, and (4) suffer from no central nervous system disorder (including Alzheimer's disease, amyotrophic lateral sclerosis (ALS), and behavioral disorders).

The primary sampling unit was the household located within a radius of, at most, $5 \mathrm{~km}$ from the major road junctions in the city. Data collectors received assistance from the city planning department to delineate a $5 \mathrm{~km}$ radius from each traffic circle and make available the list of major intersections. A random sample of reporting units were drawn proportional to size. The secondary sampling units consisted of random subsampling within the reporting units to obtain a sample of households according to a household list established by the survey team leader and community representatives. The tertiary sampling units were a single member per household, preferably the household head. To obtain the required sample size for this study, a multistage sample design formula was used with margin of error for estimates of the whole population [12]. The combined response rate was $96.0 \%$, for a final sample size of 1093 .

2.3. Data Collection. To increase the survey response rate, the community leaders were consulted to assist in recruiting data collectors from within their communities. The data collectors were a mix of undergraduates and graduates students of sociology, geography, and medicine. These interviewers were extensively trained with respect to the survey procedures and questionnaire. The data collectors were also specifically trained to ensure that the participants are completely informed of their rights prior to obtaining consent. The survey collected detailed information on respondents at their premises on waste disposal practice. It also asked about knowledge and safety behavior regarding household waste management. The survey questionnaire was constructed by the researchers after an extensive literature search on previous related topics $[9,10]$. The reliability coefficient (as assessed by Cronbach's alpha) for this study was excellent, at 0.90 , and excellent validity statistics have been previously reported $[13,14]$.

In this study, three variables are used to represent the outcomes measures: community residents' waste disposal practice, knowledge of community residents concerning the health effect of domestic waste, and safety behavior related to waste handling. The community residents' waste disposal practice derived from the question: "How your community solid waste is often disposed off?" This question consists of three values: municipal accredited dump sites, accredited private sector participation, and open land. These three values were further dichotomized into good waste disposal practice, when the residents dispose of waste directly to the permitted municipal dumpsites or make waste collected by accredited private company from the residents' premises, or poor waste disposal practice, when waste is disposed on the open land. The level of knowledge was defined as "poor" for a score less than $50 \%$ and was defined as "good" for a score of $50 \%$ and more. The level of safety behavior was defined as "safe" for those scoring higher than the mean score and was defined as "unsafe" for those scoring less than or equal to mean. All covariates collected in the survey were treated as potential confounding and adjusted.

2.4. Statistical Procedure. Descriptive analysis was performed to investigate the characteristics of different waste disposal practices of the study population. The multivariate logistic regression analyses were conducted to test the influence of socioeconomic and demographic factors on the community residents' waste disposal practice, their knowledge level of disease causation related to poor waste management, and their safety behavior with regard to waste handling. To assess the likelihood that the respondents will adopt good disposal practice of waste in their community, seven explanatory variables were considered: age, sex, marital status, education attainment, income group, residential area, and distance to permitted dumpsite. To predict the respondents' knowledge of disease causation from waste handling and safety behavior towards waste handling, six predictors were included in the model: age, sex, marital status, education attainment, income group, and residential area. The selection of explanatory variables was based on common sense and literature $[1,15,16]$. For the components of the questionnaire, item and reliability analyses were applied. Currently, the cut-off for statistical significance is set at $P \leq 0.05$.

\section{Results}

3.1. Descriptive Statistics. Table 1 portrays the frequency distribution of socioeconomic and demographic characteristics. 
TABLE 1: Socioeconomic and demographic characteristics and solid waste disposal methods of the respondents $(N=1093)$.

\begin{tabular}{|c|c|c|c|c|c|}
\hline \multirow{3}{*}{ Variables } & \multirow{3}{*}{ Frequency (\%) } & \multicolumn{4}{|c|}{ Waste disposal methods } \\
\hline & & MAD* & $\mathrm{APD}^{*}$ & Open land & Burning \\
\hline & & $N(\%)$ & $N(\%)$ & $N(\%)$ & $N(\%)$ \\
\hline Overall & $1093(100 \%)$ & $221(20.2 \%)$ & $271(24.8 \%)$ & $452(41.4 \%)$ & $149(13.6 \%)$ \\
\hline \multicolumn{6}{|l|}{ Age group } \\
\hline $15-39$ & $641(58.6 \%)$ & $89(13.9 \%)$ & $216(33.7 \%)$ & $227(35.4 \%)$ & $109(17.0 \%)$ \\
\hline $40-59$ & $378(34.6 \%)$ & $113(29.9 \%)$ & $49(13.0 \%)$ & $214(56.6 \%)$ & $2(0.5 \%)$ \\
\hline$\geq 60$ & $74(6.8 \%)$ & $19(25.7 \%)$ & $6(8.1 \%)$ & $11(14.9 \%)$ & $38(51.4 \%)$ \\
\hline \multicolumn{6}{|l|}{ Sex } \\
\hline Male & $351(32.1 \%)$ & $104(29.6 \%)$ & $93(26.5 \%)$ & $114(32.5 \%)$ & $40(11.4 \%)$ \\
\hline Female & $742(67.9 \%)$ & $117(15.8 \%)$ & $178(24.0)$ & $338(45.6)$ & $109(14.7)$ \\
\hline \multicolumn{6}{|l|}{ Marital status } \\
\hline Single & $210(19.2 \%)$ & $41(19.5 \%)$ & $55(26.2 \%)$ & $80(38.1 \%)$ & $34(16.2 \%)$ \\
\hline Married & $742(67.9 \%)$ & $151(20.4 \%)$ & $179(24.1 \%)$ & $313(42.2 \%)$ & $99(13.3 \%)$ \\
\hline Divorced & $54(4.9 \%)$ & $16(29.6 \%)$ & $18(33.3 \%)$ & $15(27.8 \%)$ & $5(9.3 \%)$ \\
\hline Widowed & $87(8.0 \%)$ & $13(14.9 \%)$ & $19(21.8 \%)$ & $44(50.6 \%)$ & $11(12.6 \%)$ \\
\hline \multicolumn{6}{|l|}{ Education attainment } \\
\hline None & $565(51.7 \%)$ & $93(16.5 \%)$ & $88(15.6 \%)$ & $307(54.3 \%)$ & $77(13.6 \%)$ \\
\hline Primary & $140(12.8 \%)$ & $19(13.6 \%)$ & $33(23.6 \%)$ & $67(47.9 \%)$ & $21(15.0 \%)$ \\
\hline Secondary & $308(28.2 \%)$ & $74(24.0 \%)$ & $119(36.6 \%)$ & $66(21.4 \%)$ & $49(15.9 \%)$ \\
\hline Tertiary & $80(7.3 \%)$ & $35(43.8 \%)$ & $31(38.8 \%)$ & $12(15.0 \%)$ & $2(2.5 \%)$ \\
\hline \multicolumn{6}{|l|}{ Household income } \\
\hline Less than 250001 & $639(58.5 \%)$ & $71(11.1 \%)$ & $47(7.4 \%)$ & $382(59.8 \%)$ & $139(21.8 \%)$ \\
\hline 250001 to 450000 & $146(13.4 \%)$ & $37(25.3 \%)$ & $51(34.9 \%)$ & $56(38.4 \%)$ & $2(1.4 \%)$ \\
\hline 450001 to 650000 & $91(8.3 \%)$ & $62(68.1 \%)$ & $27(29.7 \%)$ & $2(2.2 \%)$ & 0 \\
\hline 650001 to 850000 & $127(11.6 \%)$ & $19(15.0 \%)$ & $107(84.3 \%)$ & $1(0.8 \%)$ & 0 \\
\hline More than 850000 & $90(8.2 \%)$ & $32(35.6 \%)$ & $39(43.3 \%)$ & $11(12.2 \%)$ & $8(8.9 \%)$ \\
\hline \multicolumn{6}{|l|}{ Residential area } \\
\hline Unplanned residential area & $776(71.0 \%)$ & $86(11.1 \%)$ & $121(15.6 \%)$ & $429(55.3 \%)$ & $140(18.0 \%)$ \\
\hline Planned residential area & $317(29.0 \%)$ & $135(42.6 \%)$ & $150(47.3 \%)$ & $23(7.3 \%)$ & $9(2.8 \%)$ \\
\hline \multicolumn{6}{|l|}{ Distance to permitted dumpsite } \\
\hline Less than 50 meters & $62(5.7 \%)$ & $32(51.6 \%)$ & $26(41.9 \%)$ & $3(4.8 \%)$ & $1(1.6 \%)$ \\
\hline Between 50 and 100 meters & $231(21.1 \%)$ & $67(29.0 \%)$ & $135(58.4 \%)$ & $26(11.3 \%)$ & $3(1.3 \%)$ \\
\hline More than 100 meters & $627(57.4 \%)$ & $98(15.6 \%)$ & $75(12.0 \%)$ & $354(56.5 \%)$ & $100(15.9 \%)$ \\
\hline Over 200 meters & $173(15.8 \%)$ & $24(13.9 \%)$ & $35(20.2 \%)$ & $69(39.9 \%)$ & $45(26.0 \%)$ \\
\hline
\end{tabular}

*MAD: municipal accredited dumpsites; APS: accredited private sector.

There were a total of 1093 respondents. The mean age $( \pm$ standard deviation) was $39.4 \pm 13.3$ years, corresponding to an age range from 15 to 71 years. The mean income of the respondents was 372000 Guinean Francs (GNF) (SD \pm 299500), ranging from 21000 to 1850000 GNF.

Table 1 also identifies four remarkable methods of waste disposal. Waste disposed in an open land makes up a large proportion $(41.4 \%)$ followed, respectively, by accredited private sector $(24.8 \%)$, municipal accredited dumpsites $(20.2 \%)$, and burning (12.6\%). When analyzing waste disposal methods by socioeconomics and demographic aspects, we can quickly identify that the respondents in the age group of 15-24 years often dispose of waste in the open land (39.8\%) or by burning (32.1\%). The respondents aged $30-39$ years either frequently make their waste collected by an accredited private company $(45.2 \%)$ or discard waste in an open land (33.1\%). The most frequent preferred waste disposal method of the respondents in the age group of 40-49 years is open land (56.9\%) or municipal accredited dumpsites (30.1\%). Respondents aged 50-59 years often throw waste in an open land (56.2\%), while those above 60 years of age burn waste in the environment (51.4\%). A considerable greater proportion of women $(45.6 \%)$ discriminately dispose of waste in the open land compared to men (32.5\%). Respondents having no education attainment (54.3\%) and those with primary school level (47.9\%) often dispose of waste in the open land, while the respondents with secondary (36.6\%) and tertiary (38.8\%) schooling background often favored private companies.

Respondents having an income less than 250001 (59.8\%) and income between 250001 and 450000 (38.4\%) frequently 
TABLE 2: Knowledge of the health effects and safety behavior of the respondents regarding waste handling $(N=1093)$.

\begin{tabular}{|c|c|c|}
\hline Questions with correct responses & $N(\%)$ correct responses & $95 \% \mathrm{CI}$ \\
\hline \multicolumn{3}{|l|}{ Knowledge } \\
\hline Is poor waste disposal harmful? (Yes) & $1052(96.2 \%)$ & {$[0.950,0.972]$} \\
\hline Can surface water/ground water/piped water be contaminated at any time? (Yes) & $397(36.3 \%)$ & {$[0.335,0.392]$} \\
\hline Are children's feces as dangerous as those of adults? (Yes) & $400(36.6 \%)$ & {$[0.338,0.395]$} \\
\hline Are these following diseases related to poor waste disposal? & & {$[0.603,0.660]$} \\
\hline Cholera (yes) & $691(63.2 \%)$ & {$[0.603,0.660]$} \\
\hline Typhoid (yes) & $719(65.8 \%)$ & {$[0.629,0.685]$} \\
\hline Dysentery (yes) & $57(5.2 \%)$ & {$[0.041,0.067]$} \\
\hline Malaria (yes) & $569(52.1 \%)$ & {$[0.491,0.550]$} \\
\hline Diarrhea (yes) & $261(23.9 \%)$ & {$[0.215,0.265]$} \\
\hline Injury (yes) & $16(1.5 \%)$ & {$[0.009,0.024]$} \\
\hline Respiratory infection (yes) & $44(4.0 \%)$ & {$[0.030,0.054]$} \\
\hline \multicolumn{3}{|l|}{ Safety behavior } \\
\hline Do your children play near the solid waste? (No) & $286(26.2 \%)$ & {$[0.237,0.289]$} \\
\hline Do you buy any food from shops near solid waste? (No) & $521(47.7 \%)$ & {$[0.447,0.506]$} \\
\hline Do you properly wash your hands after waste disposal? (Yes) & $564(51.6 \%)$ & {$[0.486,0.546]$} \\
\hline Do you drink boiled water? (Yes) & $97(8.9 \%)$ & {$[0.073,0.107]$} \\
\hline Do you throw garbage daily? (Yes) & $549(50.2 \%)$ & {$[0.473,0.532]$} \\
\hline Do you usually keep garbage near the outside door? (No) & $602(55.1 \%)$ & {$[0.521,0.580]$} \\
\hline Do you leave the garbage unprotected near the outside door? (No) & $292(26.7 \%)$ & {$[0.242,0.294]$} \\
\hline Do you allow the rubbish container to overflow? (No) & $526(48.1 \%)$ & {$[0.452,0.511]$} \\
\hline $\begin{array}{l}\text { Do you wash the rubbish container with soap and water or clean with dry earth or } \\
\text { sand? (Yes) }\end{array}$ & $113(10.3 \%)$ & {$[0.087,0.123]$} \\
\hline Are children feces thrown away with other household waste? (No) & $477(43.6 \%)$ & {$[0.407,0.466]$} \\
\hline $\begin{array}{l}\text { Do you usually treat water from unprotected and suspicious surface, ground, and } \\
\text { piped sources before use? (Yes) }\end{array}$ & $125(11.4 \%)$ & {$[0.097,0.135]$} \\
\hline Do you sleep under a mosquito net? (Yes) & $792(72.5 \%)$ & {$[0.697,0.750]$} \\
\hline
\end{tabular}

dispose of waste in an open land, while respondents with income from 450001 to 650000 (68.1\%) often dispose of waste in municipal permitted dumpsites. Evidently, the respondents with income between 650001 and 850000 (84.3\%) and more than $850000(43.3 \%)$ commonly preferred accredited private sector for waste collection.

While respondents residing in unplanned neighborhood make up a larger percentage in dropping waste in the open land $(55.3 \%)$, the respondents in planned residential areas appeared to either be affiliated to waste collection companies $(47.3 \%)$ or take their waste to permitted municipal dumpsites (42.6\%). Residents residing less than 50 meters $(51.6 \%)$ or between 50 and 100 meters (58.4\%) away from permitted municipal dumpsites, respectively, dispose of their waste at the accredited municipal dumpsite and make their waste collected by private companies, but the respondents residing at more than 100 meters and over 200 meters away from permitted municipal dumpsites, respectively, discriminately dispose of their waste in the open land (56.5\% versus $39.9 \%$ ) or by burning ( $15.9 \%$ versus $26.0 \%$ ).

Table 2 illustrates the knowledge of the respondents regarding waste related disease causation. Satisfactorily, $96.2 \%$ of the respondents were aware of the fact that reckless handling of waste must be harmful to human health. Unfortunately, $63.7 \%$ were unaware of the possible contamination of host such as surface, ground, and piped water at any time as a result of poor waste management. Likewise, $63.4 \%$ of the respondents believe that poor disposal of children's feces has no adverse health effects. Concerning the evaluation of the respondents about their knowledge of the diseases caused by poor management of waste, $65.8 \%, 63.2 \%$, and $52.1 \%$ of the respondents are conscious that, respectively, typhoid, cholera, and malaria can result from poor waste handling. A very few people believe that diarrhea (23.9\%), dysentery (5.2\%), respiratory infection $(4.0 \%)$, and injury (1.5\%) might be the result of poor waste handling.

Table 2 delineates the safety behavior of the respondents in relation to waste management. Interestingly, $51.6 \%$ of the respondents adopt an important aspect of personal hygiene; that is, they properly wash their hand after waste disposal. Importantly, $50.2 \%, 55.1 \%$, and $72.5 \%$ of the respondents, respectively, throw garbage daily, usually keep garbage near the outside door, and currently sleep under a mosquito net. Other aspects of safety behavior are nevertheless cause of concern; the respondents do not prevent their children from playing near the solid waste (73.8\%), they leave the garbage 
TABLE 3: Binary logistic regression model of association between solid waste disposal methods and socioeconomic and demographic characteristics of residents $(N=1093)$.

\begin{tabular}{|c|c|c|c|c|c|}
\hline \multirow{2}{*}{ Characteristics } & \multirow{2}{*}{ Good disposal practice $N(\%)$} & \multicolumn{2}{|c|}{ Unadjusted } & \multicolumn{2}{|c|}{ Adjusted } \\
\hline & & OR (95\% CI) & $P$ value & OR (95\% CI) & $P$ value \\
\hline \multicolumn{6}{|l|}{ Age } \\
\hline $15-39$ & $305(47.6 \%)$ & $0.56(0.34-0.93)$ & 0.03 & $0.46(0.20-1.07)$ & 0.07 \\
\hline $40-59$ & $162(42.9 \%)$ & $0.68(0.40-1.15)$ & 0.15 & $0.65(0.32-1.33)$ & 0.24 \\
\hline$\geq 60$ & $25(33.8 \%)$ & Reference & & Reference & \\
\hline \multicolumn{6}{|l|}{ Sex } \\
\hline Female & $295(39.8 \%)$ & $1.94(1.50-2.51)$ & 0.00 & $2.50(1.46-4.28)$ & 0.00 \\
\hline Male & $197(56.1 \%)$ & Reference & & Reference & \\
\hline \multicolumn{6}{|l|}{ Marital status } \\
\hline Single & $96(45.7 \%)$ & $0.69(0.41-1.16)$ & 0.16 & $0.63(0.27-1.46)$ & 0.28 \\
\hline Married & $330(44.5 \%)$ & $0.73(0.46-1.15)$ & 0.17 & $0.77(0.36-1.65)$ & 0.50 \\
\hline Divorced & $34(63.0 \%)$ & $0.34(0.17-0.69)$ & 0.00 & $0.28(0.10-0.82)$ & 0.02 \\
\hline Widowed & $32(36.8 \%)$ & Reference & & Reference & \\
\hline \multicolumn{6}{|l|}{ Education attainment } \\
\hline None & $181(32.0 \%)$ & $10.0(5.47-18.28)$ & 0.00 & $3.02(1.26-7.20)$ & 0.01 \\
\hline Primary & $52(37.1 \%)$ & $7.98(4.08-15.61)$ & 0.00 & $2.19(0.82-5.84)$ & 0.12 \\
\hline Secondary & $193(62.7 \%)$ & $2.81(1.51-5.23)$ & 0.00 & $1.59(0.63-4.01)$ & 0.33 \\
\hline Tertiary & $66(82.5 \%)$ & Reference & & Reference & \\
\hline \multicolumn{6}{|l|}{ Household income } \\
\hline Less than 250001 & $118(18.5 \%)$ & $16.50(9.57-28.43)$ & 0.00 & $1.44(0.63-3.26)$ & 0.00 \\
\hline 250001 to 450000 & $88(60.3 \%)$ & $2.46(1.35-4.51)$ & 0.00 & $0.27(0.11-0.64)$ & 0.00 \\
\hline 450001 to 650000 & $89(97.8 \%)$ & $0.08(0.02-0.37)$ & 0.00 & $0.02(0.01-0.12)$ & 0.00 \\
\hline 650001 to 850000 & $126(99.2 \%)$ & $0.03(0.0-0.23)$ & 0.00 & $0.02(0.00-0.19)$ & 0.00 \\
\hline More than 850000 & $71(78.9 \%)$ & Reference & & Reference & \\
\hline \multicolumn{6}{|l|}{ Residential area } \\
\hline Unplanned residential area & $207(26.7 \%)$ & $24.48(16.43-36.47)$ & 0.00 & $5.81(3.25-10.38)$ & 0.00 \\
\hline Planned residential area & $285(89.9 \%)$ & Reference & & Reference & \\
\hline \multicolumn{6}{|l|}{ Distance to permitted dumpsite } \\
\hline Less than $50 \mathrm{~m}$ & $58(93.5 \%)$ & $0.04(0.12-0.10)$ & 0.00 & $0.16(0.05-0.57)$ & 0.00 \\
\hline Between 50 and $100 \mathrm{~m}$ & $202(87.4 \%)$ & $0.07(0.05-0.12)$ & 0.00 & $0.72(0.35-1.45)$ & 0.35 \\
\hline More than $100-200 \mathrm{~m}$ & $173(27.6 \%)$ & $1.36(0.95-1.96)$ & 0.10 & $1.91(1.15-3.17)$ & 0.01 \\
\hline Over 200 meters & $59(34.1 \%)$ & Reference & & Reference & \\
\hline$x^{2}$ & & & & 697.471 & \\
\hline df & & & & 14 & \\
\hline$\%$ & & & & 85.8 & \\
\hline
\end{tabular}

unprotected near the outside door (73.3\%), they do not often wash the rubbish container with soap and water or clean with dry earth or sand (89.7\%), and they do not usually treat water from unprotected and suspicious surface, ground, and piped sources before use (86.6\%).

3.2. Household Waste Management Practice. In Table 3, the logistic regression model showed that the variables such as sex, education attainment, marital status, household income, residential area, and the distance of the respondents away from the permitted dumpsite made a statistically independent contribution to the model. The strongest and isolate predictors of poor waste disposal practice were residential area, education attainment, and sex with respective odd ratios of 5.81, 3.02, and 2.50. Odd ratio for income indicates little change in the likelihood of poor waste disposal. People who are residing 50 meters away from municipal permitted dumpsites were less likely to poorly dispose of waste with an odd ratio of 0.04 (Table 3 ).

3.3. Household Knowledge of Waste Related Disease Causation. From Table 4, the logistic regression model showed that only sex, education attainment, and income made significant contributions to prediction. The odds of a woman being knowledgeable of the health effects related to waste mismanagement were 0.59 times lesser than the odds for man. In the 
TABLE 4: Binary logistic regression model of association between knowledge level of the respondents regarding waste related disease causation and socioeconomic and demographic characteristics of residents $(N=1093)$.

\begin{tabular}{|c|c|c|c|c|c|}
\hline \multirow{2}{*}{ Characteristics } & \multirow{2}{*}{ Good knowledge $N(\%)$} & \multicolumn{2}{|c|}{ Unadjusted } & \multicolumn{2}{|c|}{ Adjusted } \\
\hline & & OR (95\% CI) & $P$ value & OR $(95 \% \mathrm{CI})$ & $P$ value \\
\hline \multicolumn{6}{|l|}{ Age } \\
\hline $15-39$ & $247(38.5 \%)$ & $1.69(0.99-2.90)$ & 0.06 & $0.80(0.40-1.61)$ & 0.53 \\
\hline $40-59$ & $142(37.6 \%)$ & $1.63(0.93-2.83)$ & 0.09 & $0.83(0.46-1.51)$ & 0.54 \\
\hline$\geq 60$ & $20(27.0 \%)$ & Reference & & Reference & \\
\hline \multicolumn{6}{|l|}{ Sex } \\
\hline Female & $246(33.2 \%)$ & $0.57(0.44-0.74)$ & 0.00 & $0.59(0.39-0.89)$ & 0.01 \\
\hline Male & $163(46.4 \%)$ & Reference & & Reference & \\
\hline \multicolumn{6}{|l|}{ Marital status } \\
\hline Single & $86(41.0 \%)$ & $1.39(0.82-2.34)$ & 0.22 & $1.33(0.71-2.49)$ & 0.38 \\
\hline Married & $281(37.9 \%)$ & $1.22(0.76-1.95)$ & 0.41 & $1.65(0.93-2.95)$ & 0.09 \\
\hline Divorced & $13(24.1 \%)$ & $0.63(0.30-1.37)$ & 0.24 & $0.44(0.18-1.06)$ & 0.07 \\
\hline Widowed & $29(33.3 \%)$ & Reference & & Reference & \\
\hline \multicolumn{6}{|l|}{ Education attainment } \\
\hline None & $118(20.9 \%)$ & $0.10(0.06-0.17)$ & 0.00 & $0.08(0.04-0.15)$ & 0.00 \\
\hline Primary & $35(25.0 \%)$ & $0.13(0.07-0.24)$ & 0.00 & $0.11(0.06-0.23)$ & 0.00 \\
\hline Secondary & $198(64.3 \%)$ & $0.68(0.40-1.18)$ & 0.00 & $0.66(0.35-1.22)$ & 0.10 \\
\hline Tertiary & $58(72.5 \%)$ & Reference & & Reference & \\
\hline \multicolumn{6}{|l|}{ Household income } \\
\hline Less than 250001 & $178(27.9 \%)$ & $0.51(032-0.79)$ & 0.00 & $1.26(0.66-2.42)$ & 0.49 \\
\hline 250001 to 450000 & $57(39.0 \%)$ & $0.84(0.49-1.43)$ & 0.56 & $2.07(1.01-4.26)$ & 0.05 \\
\hline 450001 to 650000 & $64(70.3 \%)$ & $3.10(1.68-5.72)$ & 0.00 & $5.10(2.44-10.66)$ & 0.00 \\
\hline 650001 to 850000 & $71(55.9 \%)$ & $1.66(0.96-2.86)$ & 0.07 & $1.46(0.76-2.81)$ & 0.25 \\
\hline More than 850000 & $39(56.7 \%)$ & Reference & & Reference & \\
\hline \multicolumn{6}{|l|}{ Residential area } \\
\hline Unplanned residential area & $237(30.5 \%)$ & $0.37(0.28-0.49)$ & 0.00 & $0.83(0.53-1.30)$ & 0.41 \\
\hline Planned residential area & $172(54.3 \%)$ & Reference & & Reference & \\
\hline$x^{2}$ & & & & 290.863 & \\
\hline $\mathrm{df}$ & & & & 14 & \\
\hline$\%$ & & & & 76.7 & \\
\hline
\end{tabular}

same breath, the respondents having no education, primary education, and secondary education were, respectively, less likely to know the implication of waste in disease causation. The odd ratio value indicates that the respondents of at least a disposable income between 450001 and 650000 Guinean Francs are 5.10 times more likely to know the role of waste in disease causation (Table 4).

3.4. Household Waste Handling Safety Behavior. The result of logistic regression analysis to appraise the influence of a set of factors on the likelihood that the respondent would adopt safety behavior related to waste handling is presented in Table 5. Considering the full model, age, sex, education attainment, and income made a unique statistically significant contribution to the model. The strongest predictor of having safe behavior was being aged between 15 and 39 years which had an odd ratio of 4.21 . The respondents having female gender, no education, and income less than 250001 were less likely to adopt safe behavior (Table 5).

\section{Discussion}

This study is not only the first to develop standardized and sustainable approaches that identify broad spectrum of safety and knowledge-based variables but also the first to predict and then directly test the effects of socioeconomic and demographic factors on waste related safety and knowledge. The results of this study provide a real support for the hypothesis that the household has important roles and responsibilities in indiscriminate dumping of municipal waste. The overall proportion of community residents who adopt adequate waste disposal practice was $78.3 \%$ versus $92.0 \%$ for residents who inadequately dispose of waste. The predictors of poor waste disposal practice are residential area, education attainment, sex, income, and residence at 50 meters away from municipal permitted dumpsites. Similar findings have been reported in previous research [15-17].

In the multivariate analysis, the strongest predictor of indiscriminate disposal of waste was unplanned residential 
TABLE 5: The impact of socioeconomic and demographic factors on safety behavior of respondents regarding waste handling $(N=1093)$.

\begin{tabular}{|c|c|c|c|c|c|}
\hline \multirow{2}{*}{ Characteristics } & \multirow{2}{*}{ Safety behavior $N(\%)$} & \multicolumn{2}{|c|}{ Unadjusted } & \multicolumn{2}{|c|}{ Adjusted } \\
\hline & & OR $(95 \% \mathrm{CI})$ & $P$ value & OR (95\% CI) & $P$ value \\
\hline \multicolumn{6}{|l|}{ Age } \\
\hline $15-39$ & $306(47.7 \%)$ & $2.84(1.63-4.94)$ & 0.00 & $4.21(1.96-9.02)$ & 0.00 \\
\hline $40-59$ & $135(35.7 \%)$ & $1.73(0.98-3.06)$ & 0.06 & $1.40(0.75-2.61)$ & 0.30 \\
\hline$\geq 60$ & $18(24.3 \%)$ & Reference & & Reference & \\
\hline \multicolumn{6}{|l|}{ Sex } \\
\hline Female & $258(34.8 \%)$ & $0.40(0.31-0.52)$ & 0.00 & $0.176(0.11-0.28)$ & 0.00 \\
\hline Male & $201(57.3 \%)$ & Reference & & Reference & \\
\hline \multicolumn{6}{|l|}{ Marital status } \\
\hline Single & $107(51.0 \%)$ & $1.88(1.12-3.14)$ & 0.02 & $0.96(0.52-1.79)$ & 0.91 \\
\hline Married & $291(39.2 \%)$ & $1.17(0.73-1.85)$ & 0.52 & $0.96(0.55-1.70)$ & 0.89 \\
\hline Divorced & $30(55.6 \%)$ & $2.26(1.13-5.52)$ & 0.02 & $1.09(0.49-2.46)$ & 0.83 \\
\hline Widowed & $31(35.6 \%)$ & Reference & & Reference & \\
\hline \multicolumn{6}{|l|}{ Education attainment } \\
\hline None & $136(24.1 \%)$ & $0.17(0.10-0.28)$ & 0.00 & $0.20(0.11-0.37)$ & 0.00 \\
\hline Primary & $74(52.9 \%)$ & $0.60(0.34-1.06)$ & 0.08 & $0.37(0.19-0.74)$ & 0.01 \\
\hline Secondary & $197(64.0 \%)$ & $0.96(0.57-1.60)$ & 0.86 & $0.85(0.45-1.58)$ & 0.60 \\
\hline Tertiary & $52(65.0 \%)$ & Reference & & Reference & \\
\hline \multicolumn{6}{|l|}{ Household income } \\
\hline Less than 250001 & $240(37.6 \%)$ & $0.29(0.18-0.46)$ & 0.00 & $0.28(0.14-0.56)$ & 0.00 \\
\hline 250001 to 450000 & $49(33.6 \%)$ & $0.24(0.14-0.42)$ & 0.00 & $0.31(0.15-0.66)$ & 0.00 \\
\hline 450001 to 650000 & $25(27.5 \%)$ & $0.18(0.10-0.34)$ & 0.00 & $0.22(0.11-0.46)$ & 0.00 \\
\hline 650001 to 850000 & $84(66.1 \%)$ & $0.93(0.52-1.65)$ & 0.80 & $0.53(0.28-1.02)$ & 0.06 \\
\hline More than 850000 & $61(67.8 \%)$ & Reference & & Reference & \\
\hline \multicolumn{6}{|l|}{ Residential area } \\
\hline Unplanned residential area & $314(40.5 \%)$ & $0.81(0.62-1.05)$ & 0.11 & $2.30(1.37-3.85)$ & 0.00 \\
\hline Planned residential area & $145(45.7 \%)$ & Reference & & Reference & \\
\hline$x^{2}$ & & & & 277.409 & \\
\hline df & & & & 13 & \\
\hline$\%$ & & & & 72.1 & \\
\hline
\end{tabular}

Score mean $\pm \mathrm{SD}=4.54 \pm 1.87$.

${ }^{*} P<0.05$.

area, as evidenced by the adjusted odd ratio, 5.81 . This echoes the other major finding that indiscriminate waste disposal alongside with inadequate waste collection is strongly linked with the existence of unplanned settlements in the city [15]. Our finding seems to typically reflect the context of the study area, where the strategy to promote urban sustainability through the implementation of management and planning process is inadequate $[18,19]$. Authorities should be encouraged to promote environmental information and education of the public, which will also undoubtedly be in the authorities' own interests, in that the extent to which people participate effectively, particularly women, can only improve through education. If waste is collected by private corporations, the cost should be designed to meet the affordability of lowincome people. A responsible common effort to refurbish existing road networks in poor state and to build good paved road networks in the city and suburbs connecting all other settlements will ensure the success of waste management in the city.
Another important goal of this piece of research was to assess the community's knowledge of the health risk of improper waste management. There is ample evidence that if the community residents have immense knowledge of the harmful effect of poor waste management in general, they have a very little knowledge of the implication of waste in environmental contamination and transmission. It should be also noted that most respondents are aware that improper management of waste leads to cholera, typhoid, and malaria. However, there was a lack of understanding about some economically important diseases such as dysentery, diarrhea, respiratory infection, and injury. The poor knowledge level of the respondents was strongly and independently influenced by income, education, and sex, indicating that more effort is needed to adopt community action programs on disease prevention and health promotion with particular focus on women. For economically disadvantaged household that cannot easily have access to mass media, great outreach programs should be provided for information dissemination. 
This present study has demonstrated that the respondents are used to adopting rudimentary safety measures with regard to waste management such as proper washing of hands after waste disposal, throwing garbage daily, keeping garbage near the outside door, or sleeping under a mosquito net. Unfortunately, the respondents lack one of the most adequate safety behaviors that could be relevant in breaking the chain of contamination from noxious substances and harmful microbial and viral transmissions. That is to say, only a small number of respondents usually use treated water from unprotected and suspicious surface, ground, and piped sources. In general, the inadequate safety behavior is independently associated with age, sex, education attainment, and household income of the respondents. In response to these challenging circumstances, the Guinean government has to seek more assistance from the development partners to avail itself of financial support as well as much-valued technical assistance and advice to improve the delivery of community-based health education. To make the management of such investment efficient and effective, the Guinean government can make all effort to ensure the availability of responsible human resources that are respectful of the community rights.

The main strengths of this study are the following: it used the large sample size with three outcome measures, accounted for confounding factors, and established good survey reporting method. Interestingly, this study can address the need for comprehensive information and tools to assist policy makers and stakeholders in adjusting current programs and planning future programs. For health educators, the study will better promote healthy handling of household waste to diverse populations. And, for researchers, this study will contribute towards the improvement of data comparability.

\section{Conclusion}

This study provides evidence that household and community groups' waste disposal practice is careless with the environment. Such waste disposal practice with disregard for the possible environmental consequences is possibly influenced by specific socioeconomic status (sex, education attainment, and household income) and geographic risk factors (residential area and residents' distance to municipal permitted dumpsite). It demonstrated that the respondents not only have poor knowledge of the adverse health effect with regard to improper waste handling but also have unsafe behavior towards safety practices. This research suggests that the promotion of environmental information and education of the public and adoption of community action programs on disease prevention and health promotion will enhance comfort, environmental friendliness, and safety of the community. The government could create an environment where innovation and the promotion of knowledge can flourish. Investments in knowledge and innovation are keys to improving the country's productivity performance and increasing the community's standard of living. Future study should focus on the financial role of the government and/or the management efforts of waste collection corporations.

\section{Ethical Approval}

The study protocol was approved by the Guinean Institutional Review Board and the Medical Research Advisory Committee. The ethical approval was also obtained from municipal authorities.

\section{Competing Interests}

The author declared that there are no potential competing interests with respect to the research, authorship, and/or publication of this paper.

\section{Acknowledgments}

The author thanks Central South University in China and the Guinean Ministry of Public Health for their contributions to this study.

\section{References}

[1] O. S. Ojewale, "Intraurban analysis of domestic solid waste disposal methods in a sub-sahara African city," Journal of Waste Management, vol. 2014, Article ID 193469, 7 pages, 2014.

[2] M. Alhassan and J. Mohammed, "Households' demand for better solid waste disposal services: case study of four communities in the new juaben municipality, Ghana," Journal of Sustainable Development, vol. 6, no. 11, pp. 16-25, 2013.

[3] South Rivers, "Conakry and garbage, it is a story of flawless loyalty," 2014, http://cireass.mondoblog.org/conakry-et-lesordures-cest-une-histoire-de-fidelite-sans-faille/.

[4] A. Touré, "Incineration of household waste exacerbates the problem of waste discriminate disposal," 2008, http://ipsinternational.org/fr/_note.asp?idnews=4129.

[5] K. Mamady and S. Mafoule, "Cholera in guinea: the implication for safe water sources and sanitations," Open Journal of Preventive Medicine, vol. 4, no. 7, pp. 535-544, 2014.

[6] K. Mamady and G. Hu, "A step forward for understanding the morbidity burden in Guinea: a national descriptive study," BMC Public Health, vol. 11, article 436, 2011.

[7] S. Ishak and A. V. Dadson, "Households' awareness and perception of sanitation bye-laws in ghana: evidence from kumasi metropolis," Research Journal of Environmental and Earth Sciences, vol. 6, no. 8, pp. 402-407, 2014.

[8] T. C. Ogwueleka, "Municipal solid waste characteristics and management in Nigeria," Iranian Journal of Environmental Health Science and Engineering, vol. 6, no. 3, pp. 173-180, 2009.

[9] O. I. Okechukwu, A. A. Okechukwu, H. Noye-Nortey, and O. Agyei, "Health perception of indiscriminate waste disposal-a Ghanaian case study," Journal of Medicine and Medical Sciences, vol. 3, no. 3, pp. 146-154, 2012.

[10] B. Aroj, M. Muhammad, A. Ushahid, and M. Qasim, "Epidemiology impact of solid waste and assessment of awareness level among rural areas of Pakistan," American-Eurasian Journal of Agricultural \& Environmental Sciences, vol. 14, no. 9, pp. 831837, 2004.

[11] Wikipedia, The free encyclopedia: Conakry, http://en.wikipedia .org/wiki/Conakry.

[12] Statistics Canada, "Sample size determination and allocation," in Survey Methods and Practices, Catalogue No. 12-587-X, 
chapter 8, Authority of the Minister Responsible for Statistics Canada, Ottawa, Canada, 2003.

[13] D. George and P. Mallery, SPSS for Windows Step by Step: A Simple Guide and Reference. 11.0 Update, Allyn \& Bacon, Boston, Mass, USA, 4th edition, 2003, http://wps.ablongman.com/ wps/media/objects/385/394732/george4answers.pdf.

[14] P. Kline, The Handbook of Psychological Testing, Routledge, London, UK, 2nd edition, 2000.

[15] B. Onu, S. S. Surendran, and T. Price, "Impact of inadequate urban planning on municipal solid waste management in the Niger Delta Region of Nigeria," Journal of Sustainable Development, vol. 7, no. 6, pp. 27-45, 2014.

[16] A. G. Bogoro, Y. A. Mohammed, and Y. B. Yakubu, "Indiscriminate Solid Waste disposal in Bauchi: causes and impacts on the community and environment," Journal of Environment and Earth Science, vol. 3, no. 4, 2013.

[17] J. O. Babayemi and K. T. Dauda, "Evaluation of solid waste generation, categories and disposal options in developing countries: a case study of Nigeria," Journal of Applied Sciences \& Environmental Management, vol. 13, no. 3, pp. 83-88, 2009.

[18] S. Kouyate, Solid Waste Management in Conakry. Guinea, 2002, http://siteresources.worldbank.org/INTUSWM/Resources/ KouyateEng.pdf.

[19] M. Claude and C. George, "A transitory regime: water supply in conakry, guinea in thirsting for efficiency," in The Economics and Politics of Urban Water System Reform, M. Shirley, Ed., Pergamon/Elsevier, Guinea, West Africa, 2002, http://www .webguinee.net/bibliotheque/economie/eau/menard_clarke/ water_supply_thirsting_efficiency.html. 


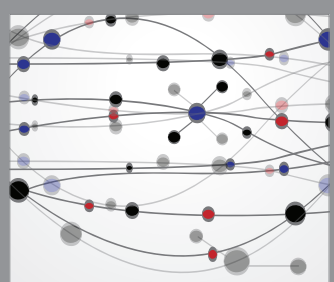

The Scientific World Journal
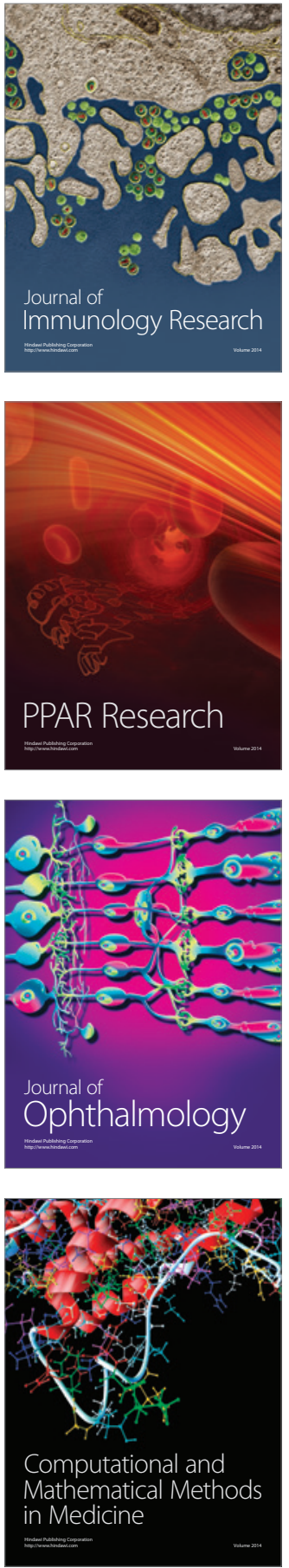

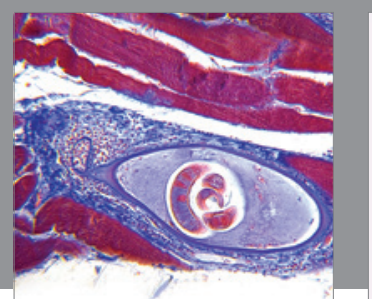

Gastroenterology Research and Practice

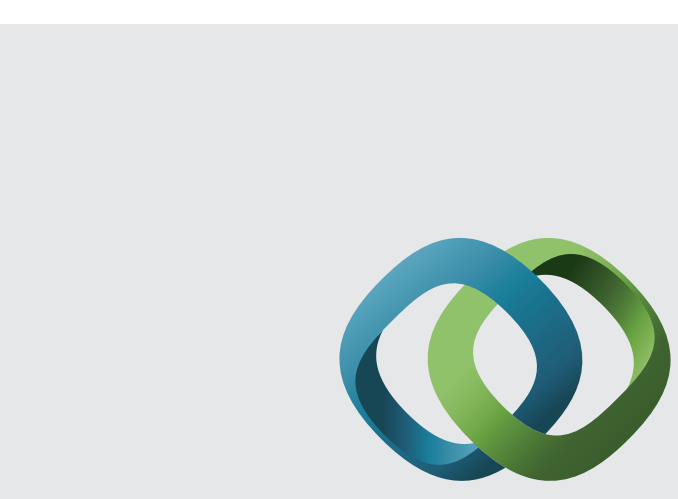

\section{Hindawi}

Submit your manuscripts at

http://www.hindawi.com
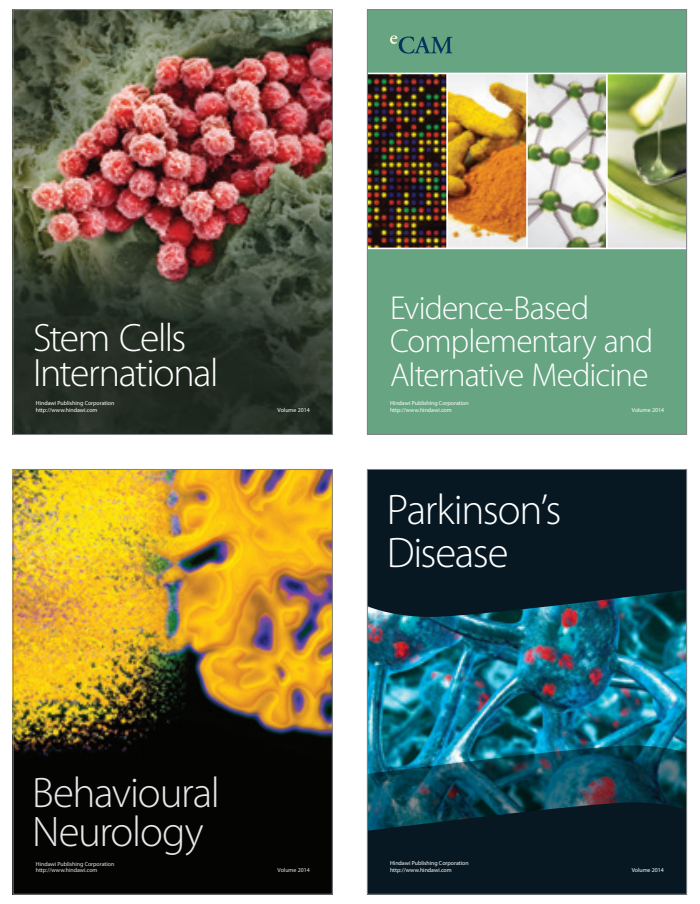
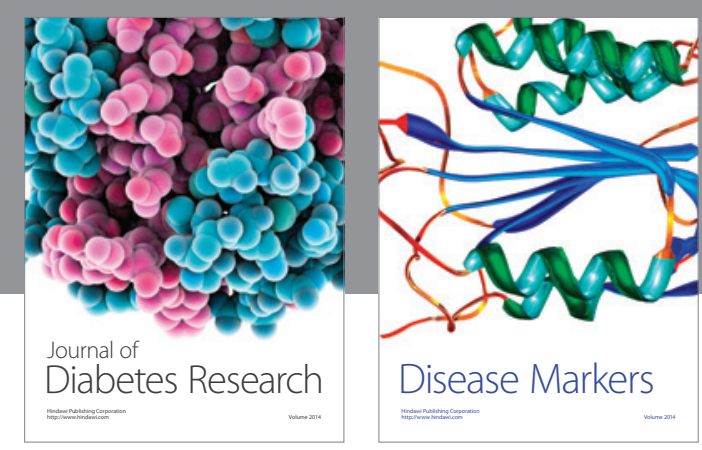

Disease Markers
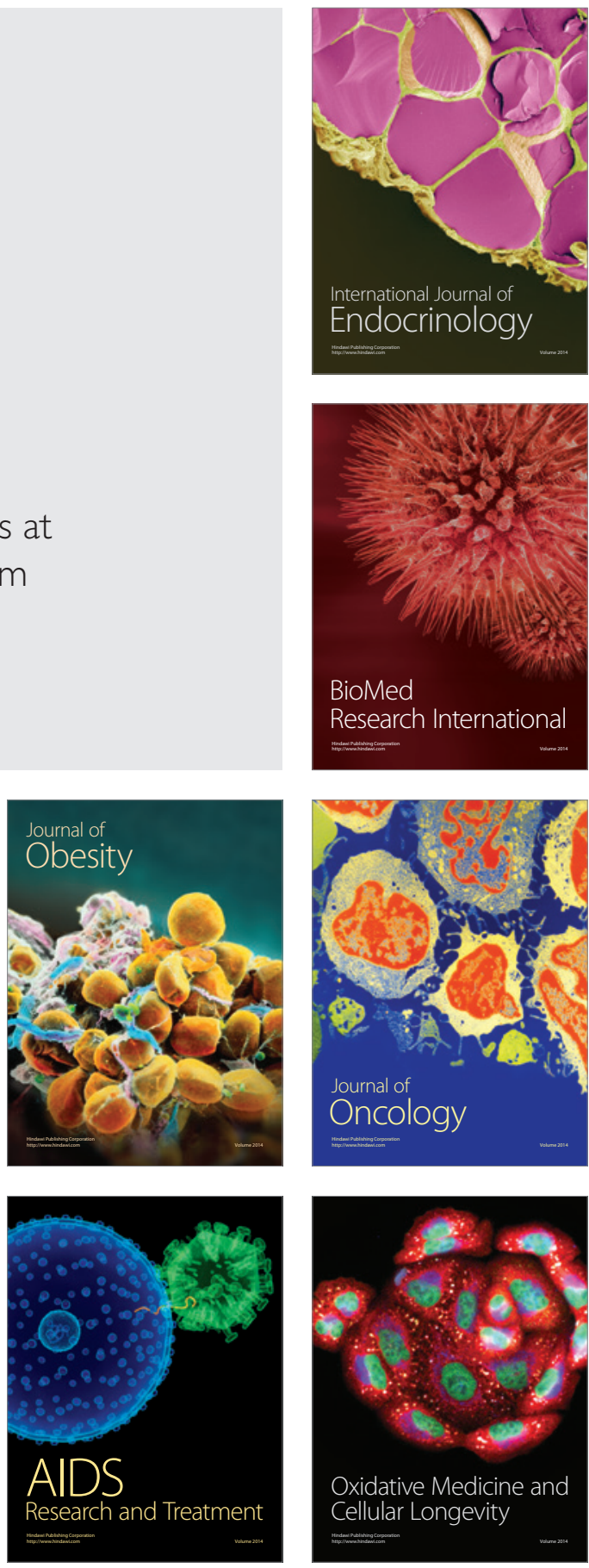